\title{
A familial syndrome of microcephaly, sparse hair, mental retardation, and seizures
}

\author{
A van Haeringen*, J A Hurst, R Savidge, $M$ Baraitser
}

\begin{abstract}
A family is described in which the father and three of his seven children have microcephaly, mild to moderate mental retardation, and sparse hair. The two affected boys have generalised seizures in addition.
\end{abstract}

Alopecia or sparse hair with microcephaly or mental retardation is a well recognised association. Moynahan ${ }^{1}$ reported brothers with mental retardation and congenital alopecia. One of the brothers had generalised seizures. Pfeiffer and Völklein ${ }^{2}$ described a brother and sister with universal alopecia, microcephaly, and mental retardation. Wessel et $a l^{3}$ reported three sibs with alopecia, seizures, and mental retardation. Baraitser $e t a l^{4}$ reported three cousins with mental retardation and alopecia in an inbred family. Shokeir ${ }^{5}$ published a four generation family with a dominantly inherited syndrome of alopecia, epilepsy, dental anomalies, and mental retardation. We describe a family with a new combination of sparse hair, microcephaly, mental retardation, and seizures in two generations.

\section{Case report}

The family pedigree is shown in fig 1. The two

Clinical Genetics Unit, The Hospital for Sick Children, Great Ormond Street, London WC1N 3JH.

$A$ van Haeringen, J A Hurst, $M$ Baraitser

Tower Hamlets Health Authority, Community and Priority Services, London.

R Savidge

Correspondence to Dr Hurst.

*Present address: Clinical Genetics Center, University Hospital, Leiden, The Netherlands.

Received for publication 8 July 1989.

Accepted for publication 2 August 1989.

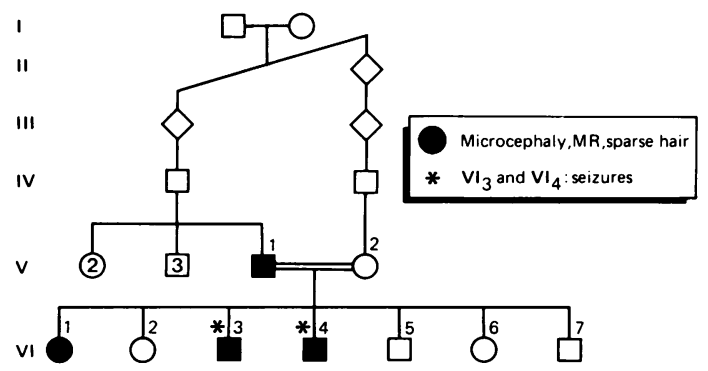

Figure 1 Pedigree showing distantly related parents.

brothers, VI.3 and VI.4, were referred to the genetic clinic for consideration of a syndrome diagnosis.

The older boy VI.3 was 7 years old. His head circumference (OFC) was $44.5 \mathrm{~cm}(4 \mathrm{~cm}$ below the 3 rd centile) and his height was $112 \mathrm{~cm}$ (10th centile). $\mathrm{He}$ attended a school for children with severe learning difficulties. Seizures developed at the age of 5 months. They are now well controlled, but his initial fit was prolonged, lasting for about 30 minutes. He had sparse hair on his scalp and eyebrows. Although the hair was sparse it grew at a normal rate. The nails and teeth were normal. There was a small skin tag anterior to the right ear.

His brother VI.4 also had sparse hair that grew normally. His seizures began at the age of 5 years. The fits were initially difficult to control and he had a mild left hemiplegia. There was mild developmental delay. At 5 years of age his OFC was $45 \mathrm{~cm}(3 \mathrm{~cm}$ below the 3 rd centile) and his height was $96.2 \mathrm{~cm}$ ( $2 \mathrm{~cm}$ below the $3 \mathrm{rd}$ centile).

The boys came to the clinic with their father (fig 2). His facial appearance is shown in fig 3 . His height was $160 \mathrm{~cm}(2 \mathrm{~cm}$ below the $3 \mathrm{rd}$ centile) and his OFC was $50 \mathrm{~cm}(4 \mathrm{~cm}$ below the $3 \mathrm{rd}$ centile). He has not had seizures. He attended school in Bangladesh but always had more difficulty with academic work than his brothers and sisters. Like his two sons described above his hair has always been sparse. Examination of his teeth and nails was normal. 
Figure 2 The father and his two affected sons (VI.3 left and VI.4 right). Note sparse hair.

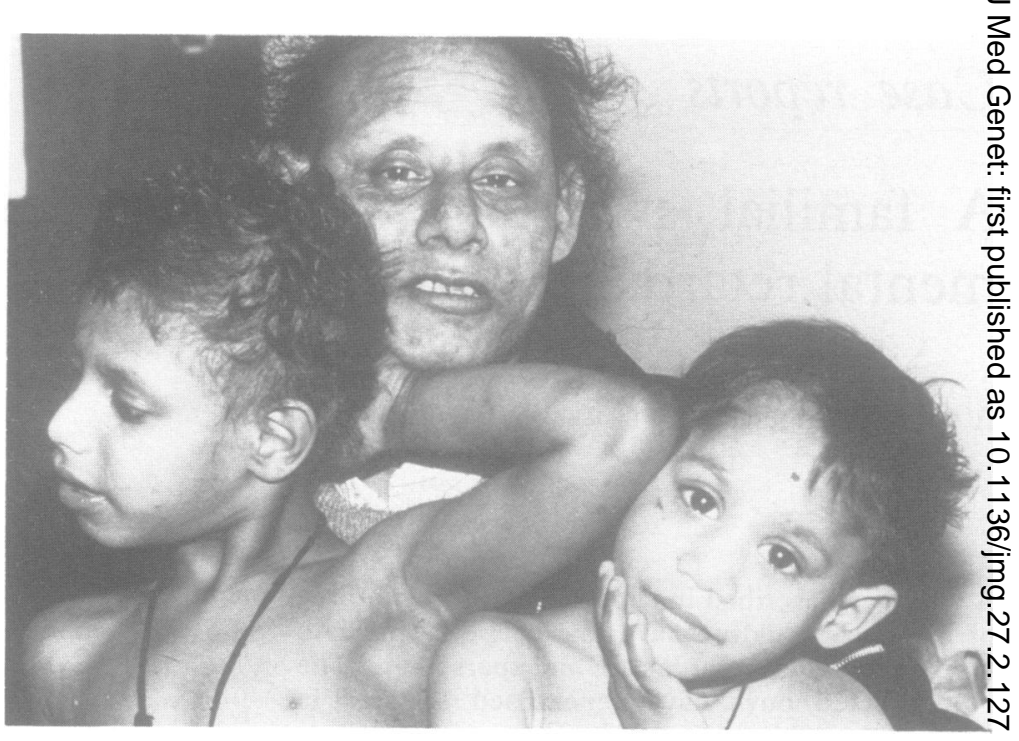

This man and his wife originate from the same small town in Bangladesh and are distantly related (fig 1). None of his brothers and sisters has sparse hair, seizures, or developmental delay.

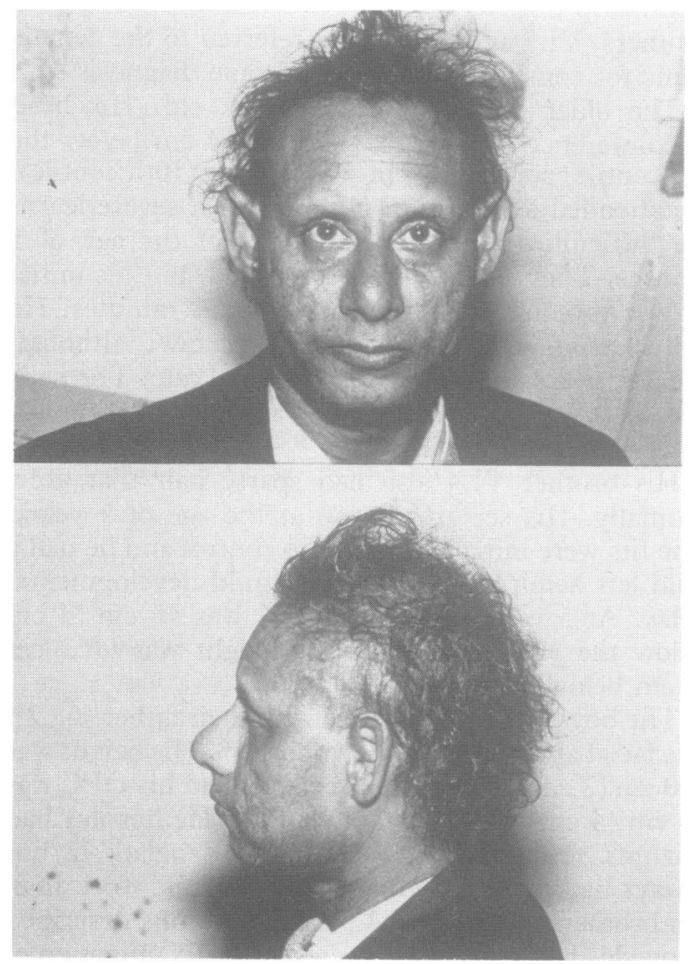

Figure 3 The father.
We went on to examine the rest of the family. The oldest affected girl (VI.1) has learning difficulties. Shem is also microcephalic (OFC $-4 \mathrm{SD}$ ) and has sparse hair. She has never had any seizures. Electro encephalograms on the two affected boys showed frequent discharges. They both have normal chromo $\overrightarrow{0}$ somes without any evidence of fragile sites. Miços? scopic investigation on the hair of one of the boys normal.

\section{Discussion}

The London Dysmorphology Database listed 28 conditions with the combination of alopecia, microcephaly, and mental retardation. Because most of these conditions have important additional mani-F festations not present in our patients, only those:which most closely resemble our family will be discussed.

Moynahan ${ }^{1}$ reported two mentally retarded brothers with alopecia until the ages of 2 and 3 years. They were not microcephalic. The parents were of normal intelligence but there was a history of alopecia in infancy on both sides of the family. One boy had seizures and his EEG showed an unusual amount of slow wave activity but no discharges. This patient had been investigated at Great Ormond Street HospitalN and the original EEG was compared to the EEG of the boys in our family. There was no similarity.

Autosomal recessive inheritance of alopecia/mentales retardation syndromes has been proposed by severale authors. Pfeiffer and Völklein ${ }^{2}$ reported a brother ando sister with universal alopecia, microcephaly, andळ mental retardation. They had no seizures. The three ${ }^{-}$ sibs described by Wessel $e t a l^{3}$ also had universal alopecia. They had seizures that started in the neo- $\frac{0}{\mathbb{D}}$ 
natal period and severe developmental delay with no acquisition of developmental milestones. Baraitser et $a l^{4}$ reported similar children who were born to consanguineous parents.

Shokeir ${ }^{5}$ described a four generation family with a dominantly inherited syndrome of alopecia, epilepsy, dental anomalies, and mental retardation. These patients were not microcephalic.

We therefore consider that our family with sparse hair, microcephaly, mental retardation, and seizures is not the same as those families reported previously and discussed above. The mode of inheritance remains uncertain. An autosomal dominant mode of inheritance for this syndrome is possible, but autosomal recessive inheritance with 'pseudo dominance' cannot be excluded because of the consanguinity in the pedigree. The parents are distantly related and it is possible that the affected father's spouse could be a carrier.

1 Moynahan EJ. Familial congenital alopecia, epilepsy, mental retardation with unusual electroencephalograms. Proc $R$ Soc Med 1962;55:411-2.

2 Pfeiffer RA, Völklein J. Congenital universal alopecia, mental deficiency, and microcephaly in two sibs. $\mathcal{f}$ Med Genet 1982;19:388-9.

3 Wessel HB, Barmada MA, Hashida Y. Congenital alopecia, seizures, and psychomotor retardation in three siblings. Pediat Neurol 1987;3:101-7.

4 Baraitser M, Carter CO, Brett EM. A new alopecia/mental retardation syndrome. $\mathcal{F}$ Med Genet 1983;20:64-5.

5 Shokeir MHK. Universal permanent alopecia, psychomotor epilepsy, pyorrhea and mental subnormality. Clin Genet 1977; 